\title{
VÍCTIMAS Y VERDUGOS: LA REPRESENTACIÓN DE LA PENA DE MUERTE EN EL CINE ESPAÑOL
}

\author{
VICTIMS AND EXECUTIONERS: THE REPRESENTATION \\ OF DEATH PENALTY IN SPANISH CINEMA
}

\author{
Concha GÓMEZ GARCÍA \\ Universidad Carlos III de Madrid \\ cogomezg@hum.uc3m.es
}

Resumen: La ejecución por garrote vil fue un recurso punitivo habitual en España hasta muy avanzado el siglo XX. Esta investigación aborda cómo se ha representado en la cinematografía española tan espinoso asunto, centrándonos en argumentos basados en hechos reales. Analizaremos cómo algunos cineastas lo esquivaron o cómo otros fusionaron la herencia esperpéntica, el sainete y la astracanada convirtiendo un film en el mejor proyectil contra la pena de muerte. Desde una estética opuesta obras más contemporáneas siguen mostrando la dificultad de la búsqueda de la verosimilitud narrativa en relatos que forman parte del imaginario colectivo de un país.

Palabas clave: Pena de muerte. Cine español. Sucesos reales. Representación audiovisual. Imaginarios colectivos.

\begin{abstract}
Execution by garotte was a common punishing method in Spain until well into the $21^{\text {st }}$ Century. This article will tackle the ways in which Spanish cinema has dealt with this thorny matter, first focusing on plots based on real facts. Attention will be paid to how some filmmakers used the esperpento heritage, the one-act farce and the astracanada as an attack against the death penalty. Using different aesthetics, films nowadays still explore the difficulty to reach verisimilitude in stories that are part of the social imaginary of the country.
\end{abstract}


Keywords: Death penalty. Spanish cinema. True stories. Audiovisual representation. Social imaginaries.

\section{INTRODUCCIÓN}

La fuerza dramática de un acto tan violento como es la ejecución de la pena de muerte por parte del Estado, la representación visual de ese momento tan pavoroso ha estado presente en todas las artes, incluso desde el nacimiento del cinematógrafo. En los últimos años del XIX, en Francia, Charles Pathé producía L'execution capitale à Berlin (1899), casi al tiempo de que en Estados Unidos se reconstruía de manera cruda y realista en Execution of Czolosz, with Panorama of Auburn Prison (Edwin S. Porter, 1901) la ejecución del anarquista autor del magnicidio del presidente William McKinley. Desde entonces, el cine norteamericano ha recurrido de manera continuada a este tema como un eficaz artefacto argumental ${ }^{1}$, mientras que en el continente europeo la representación cinematográfica de la pena capital ha estado presente de manera intermitente, coincidiendo siempre "con el auge de los movimientos dictatoriales que aplicaron sistemáticamente dicha sanción" porque "en épocas de normalidad democrática y abolición de la pena, aparece ocasionalmente" (Maroto, 2003: 127).

En todo el mundo, el cambio de unos métodos de ejecución por otros, el perfeccionamiento de los ya existentes o la aparición de nuevos sistemas se han presentado y representado ante la opinión pública como la búsqueda del procedimiento más humanitario para el reo, dando lugar a acalorados debates incluso en pleno siglo $\mathrm{XXI}^{2}$. El rey Fernando VII

\footnotetext{
${ }^{1}$ Resulta muy abultada la nómina de films que abordan la pena de muerte en el cine norteamericano. Desde la silente Capital Punishment (Hogan, 1925), pasando por su presencia en el western, los docudramas centrados en personajes como I Want to Live (Wise, 1958) o The Executioner's Song (Schiller, 1978) sobre el psicópata Gary Gilmore, hasta propuestas realizadas en pleno debate sobre su aplicación, como Dead Man Walking (Robins, 1995), The Chamber (Foley, 1996), True Crime (Eastwood, 1999) o The Green Mille (Darabont, 1999), entre otras.

${ }^{2}$ En 2016, la desastrosa ejecución de la pena de muerte en Oklahoma al reo Clayton Lockett tras aplicarle la inyección letal reavivó el debate en EEUU sobre su uso, así como las relaciones de fuerza entre partidarios y detractores de esta medida punitiva. En 2017 se ejecutaron en el mundo a 993 personas en 23 países, según datos facilitados por Amnistía Internacional: https://www. amnesty.org/es/death-penalty [18/01/2019].
} 
regaló a la Reina por su cumpleaños (1832) la abolición de la horca y la instauración del garrote en España (que permitía al reo morir sentado) porque el objetivo era "conciliar el último e inevitable rigor de la justicia con la humanidad y decencia en la ejecución de la pena capital"'3. De esa manera quedaba instaurado este avance social en nuestro país y, tal y como recordaba el narrador de Queridísimos verdugos (Martín Patino, 1977), “el garrote pasó a ser parte de lo español”, como los toros o el flamenco, una suerte de producto ibérico anclado en la cotidianidad de la vida española.

\subsection{Metodología y estado de la cuestión}

El objetivo de este trabajo es abordar la representación cinematográfica española de la pena de muerte, centrándonos principalmente en un corpus de estudio conformado por films que están basados en hechos reales, con un antecedente hipotextual que procede de la crónica de sucesos. Nos centraremos, por tanto, en Expreso de Andalucía / Il mondo sará nostro (Rovira-Beleta, 1956); El crimen de la calle Bordadores (Neville,1946); El verdugo (García Berlanga, 1963); Queridísimos verdugos (Martín Patino,1977); La noche más larga (García Sánchez, 1991); Salvador (Huerga, 2006); Las 13 rosas (Martínez Lázaro, 2007); La espalda del mundo (Corcuera, 2000), y La muerte de nadie. El enigma de Heinz Ches (Dolç, 2003). Estos títulos nos permitirán confirmar, en primer lugar, que algunos cineastas utilizaron el sainete y la comedia costumbrista para alejarse del referente real y eludir la representación de la ejecución de la pena capital. Veremos también cómo otros directores utilizaron el esperpento y la tradición solanesca como estrategias de intermedialidad para construir relatos de gran profundidad crítica contra el uso de este recurso punitivo durante el franquismo. Y, por último, constataremos las dificultades que algunos autores han experimentado para lograr verosimilitud y credibilidad en sus propuestas cuando se abordan sucesos contemporáneos o recientemente acaecidos que forman parte del imaginario colectivo del país. También queremos hacer referencia a un proyecto reciente de tratamiento documental de la pena de muerte, que se encuentra en fase de rodaje en Estados Unidos, dirigido por el cineasta

${ }^{3}$ Real Decreto de 24 de abril de 1832. Disponible en: $h t t p s: / / w w w . b o e . e s / d a t o s / p d f s / B O E / / 1832 / 050 /$ A00205-00205.pdf [18/01/2019]. 
Manuel Martín Cuenca. The Miramar Murder aborda la historia de Pablo Ibar, un americano de origen vasco que ha estado en el corredor de la muerte hasta que se ha logrado la apertura de un nuevo juicio sobre esta causa a finales de 2018 y que en el momento de escribir este artículo sigue pendiente de resolución ${ }^{4}$.

En el análisis del corpus seleccionado se combinan herramientas teóricas y metodológicas propias de la historia cultural del cine español junto al análisis textual de dichas películas, haciéndonos eco de la invitación de Santos Zunzunegui en su texto seminal "La línea general o las vetas creativas del cine español": "Más que nunca el equilibrio entre las metodologías de análisis textual y la indagación histórica (que no historicista) se convierte en consigna esencial para futuros trabajos sobre el cine español" (2005: 501).

Para la creación del marco teórico se ha realizado una revisión bibliográfica atendiendo a nociones decisivas para este estudio sobre narración factual (Genette: 1990) como inspiradora de ficciones fílmicas, así como a reflexiones sobre intermedialidad (Mitchell: 2005). Asimismo, mientras que las contribuciones bibliográficas al estudio de la pena de muerte en el cine americano han sido relevantes con las aportaciones de Dow (2000), Papke (2012) o Kozlovsky-Golan (2014), entre otras, en España las investigaciones sobre este asunto han sido escasas. Hemos considerado el estudio de Rivaya (2003), que plantea un análisis desde la perspectiva del Derecho y la moral de diez obras de la cinematografía mundial o el de Parro (2008), que estudia los distintos métodos de ejecución representados en distintos films a lo largo de la historia, siendo más inspiradoras las lecturas y propuestas que hacen determinados autores sobre obras específicas de la cinematografía española como Zunzunegui (2018), Rodríguez Solás (2016), Gordillo (2008) o Antón (2006).

\subsection{Primeras tentativas fílmicas}

El uso de la pena de muerte fue un recurso punitivo habitual en España desde mediados del XIX hasta su abolición por la Constitución

\footnotetext{
${ }^{4}$ Por razones obvias, la conclusión del film está a la espera de la sentencia definitiva y, por tanto, queda fuera de nuestro corpus de estudio. Ibar, sobrino del boxeador Urtaín, fue acusado en 1994 por asesinar al dueño de un local de alterne de Florida y sus dos bailarinas y condenado a la pena capital en el año 2000.
} 
de $1978^{5}$, pero los primeros cineastas españoles que abordaron este dramático asunto optaron por dulcificar el momento y por librar a los reos de ese traumático final. Este tratamiento amable de la pena de muerte lo encontraremos en el cine de José Buchs, tanto en el romance popular El conde de Maravillas (1927), conmutando la ejecución gracias a la generosidad de Godoy, como en El dos de Mayo (1927), con un imposible final feliz para la pareja protagonista al ser indultados en el mismo paredón (Cánovas, 2014: 43).

También se utilizó un tono de comedia para recrear las horas previas de un condenado a muerte en El misterio de la Puerta del Sol (Elías, 1929). El crimen que se le atribuía al protagonista estaba inspirado en el crimen de Ricardito, un suceso que conmocionó a la sociedad española de 1929, cuando apareció en la estación de Atocha en una maleta el cadáver descuartizado del atildado empresario catalán Pablo Casado. Las interrelaciones de realidad y ficción se erigen en vértice nuclear del argumento como se corrobora en este guiño cómplice pero el cineasta decidió que el relato transitara por terrenos más cómicos, despojándolo de cualquier detalle escabroso y obviando las connotaciones homosexuales del caso de partida. ${ }^{6}$

Distinto tratamiento tuvo la pena capital en la España de los cuarenta, cuando "el cine español aparecía distanciado de una realidad tan pregnante como la de la posguerra" (Monterde, 1995: 215). Aunque no están basadas en sucesos reales concretos, el tema de la ejecución se utilizó dentro de la exaltada retórica de la propaganda franquista que ensalzaba sus valores morales y religiosos, como en el caso de Raza (Sáenz de Heredia, 1941), salvando de la condena al hermano que representa las esencias de la sublevación, alter ego del dictador, o bien como castigo ejemplarizante para los homicidas. Por esa razón no hubo perdón o magnanimidad para los jóvenes urbanos descarriados y delincuentes de Los atracadores (RoviraBeleta, 1961), la representación más realista y cruda del cine español hasta esa fecha sobre este castigo. E igualmente quedó grabado en el imaginario colectivo el trágico final del personaje interpretado por José Luis Gómez en la adaptación cinematográfica de Pascual Duarte (Franco, 1975),

\footnotetext{
${ }^{5}$ A excepción de lo que pudieran disponer las leyes militares en tiempos de guerra.

${ }^{6}$ Ricardo Fernández, criado y amante de la víctima, fue el autor confeso de este crimen que sería trasladado a la ficción por Ricardo Franco en el film El caso del cadáver descuartizado, dentro de la serie de televisión La huella del crimen (RTVE, 1985).
} 
ejemplificando cómo el cine de la Transición se desprendía de cualquier rasgo romántico para representar de forma directa y sin adornos el ajuste de cuentas del Estado contra el individuo.

\section{RELATOS FACTUALES, RELATOS FICCIONALES}

Pero el objeto de nuestro estudio es un corpus fílmico que podría enmarcarse bajo la etiqueta de basado en hechos reales que "remite a un supuesto referente prenarrativo" (Carrera, Talens, 2018: 142). Tales acontecimientos (ejemplos en su mayoría de la crónica criminal, de la crónica negra) recreados por los cineastas, resultan ser, en realidad, relatos factuales procedentes de manera directa o indirecta de un eslabón mediador que suele obviarse cuando se alude al referente (hechos reales) como inspirador de la ficción fílmica o motor del relato documental, y que, como venimos estudiando en otros trabajos (Gómez y SánchezMesa, 2011), es, esencialmente, el periodismo y el periódico, proveedor de excepción de eso que Genette denominaba narración factual en su modalidad relato de la actualidad (Genette, 1990: 756-757).

Parecería, a tenor de este marco teórico, que nuestras disquisiciones pudieran estar abocadas a moverse dentro de los códigos del realismo, un término y concepto que sabemos, como señalaba Raymond Williams, resulta "A highly variable and inherently complex term" (1977: 73). Sin embargo, como enseguida veremos, la especificidad de la línea general del cine español nos situará más bien ante distintos estilos de desmontaje o superación de los códigos realistas en una rica y multiforme hibridación de formas y géneros artísticos, fundamentalmente populares, que penetran también en películas que abordan un tema y una realidad tan trágicas y sobrecogedoras como la pena de muerte.

\subsection{La adaptación del suceso criminal en tiempos de dictaduras}

No son muchos, proporcionalmente hablando, los cineastas españoles que se aproximan al material argumental sustentado en hechos reales, a diferencia de lo que sucede en otras cinematografías donde este cine tiene arraigada tradición, pero el asunto se vuelve más espinoso aún si el plot device es la pena de muerte. Siguiendo la estela de lo dicho más arriba, Francisco Rovira-Beleta, director de Expreso de Andalucía / Il 
mondo sará nostro (1956), decidió otorgar un destino menos traumático a los protagonistas de su film que el que tuvieron los verdaderos implicados en el suceso real. La película se basa en el crimen del Expreso de Andalucía, ocurrido el 11 de abril de 1924, cuando un grupo de atracadores asaltó el Tren Expreso de Andalucía, desvalijando el coche correo y asesinando a los funcionarios que lo custodiaban. Los hechos causaron gran impacto en la sociedad por la crueldad del suceso, pero, sobre todo, por la diligencia de la dictadura de Primo de Rivera en descubrir a los autores y en aplicar la sentencia de muerte. El peso de la Ley caía de manera fulminante sobre los acusados el 9 de mayo de 1924, apenas 24 horas después del Consejo de Guerra que se solventó en una sola jornada maratoniana. La ejecución a garrote vil se llevó a cabo tan rápidamente porque, según informaba $A B C$, el marqués de Estella consideraba que "la opinión pública exigía un castigo ejemplar"'.

En la adaptación cinematográfica de este caso, Rovira-Beleta, mantuvo las líneas argumentales del referente, pero optó por realizar una transpolación temporal de los acontecimientos, situando el relato en el Madrid de 1954. Esos treinta años de diferencia le sirvieron para otorgar al film un planteamiento más contemporáneo, más "negro", además de para despojar a la película de cualquier connotación política relacionada con la dictadura de Primo de Rivera y, por tanto, evitar cualquier símil con el dictador del momento. La película se centró en la miseria moral de los personajes, pero eso no impidió numerosos problemas con la censura, que exigió insistentemente que sus protagonistas fueran "seres repulsivos y no despertaran simpatías bajo ningún concepto en los espectadores". Aunque no fuera el Estado quien cumpliera la ejecución, los jóvenes delincuentes de esta adaptación cinematográfica no se libraron de la muerte.

\subsection{La tradición del sainete y la comedia costumbrista: Neville y el crimen de la calle Bordadores}

Resulta particularmente interesante el modelo creativo establecido por algunos cineastas para interpretar un suceso real, como es la aplica-

\footnotetext{
${ }^{7} A B C, 9$ de mayo de 1924, p. 9.

${ }^{8}$ Expediente de Censura. Archivo General de la Administración (AGA), Sección Cultura, 36/04763, Expediente 194/55.
} 
ción de la pena de muerte a un personaje concreto, a partir de tradiciones de cultura popular hispanas en las que se introducen algunos elementos críticos (Zunzunegui, 2005, 2018). Para ello nos apoyaremos también en la tesis, desarrollada en los estudios comparatistas y de la intermedialidad de que "All media are mixed media" (Mitchell, 2005: 399) y, por tanto, en la constatación de que la historia del cine y el desarrollo de su lenguaje y códigos semióticos registran una continua ósmosis y relación dialógica con recursos y estrategias formales provenientes de otras artes y géneros discursivos (pintura, teatro, fotografía, novela, poesía, crónica periodística), relación especialmente intensa en el caso de los géneros populares (sainete, zarzuela, farsa, romance de ciego, teatro de títeres, etc.).

El primer caso del que nos ocuparemos es el del escritor y cineasta Edgar Neville, quien transformó, a través de los modelos genéricos del sainete, la comedia costumbrista y el folletín melodramático, con alguna pincelada de la astracanada, el famoso crimen de la calle Fuencarral - un suceso que significó el nacimiento del periodismo sensacionalista en nuestro país a finales del XIX-, en El crimen de la calle Bordadores (1946). A pesar de las extraordinarias dificultades censoras que el cineasta encontró para trasladar al cine este mediático caso ${ }^{9}$, Neville decidió seguir adelante eludiendo cualquier detalle escabroso. En el suceso real, Higinia Balaguer fue la última persona que se ejecutó públicamente en Madrid, el 19 de julio de 1890, tras celebrarse un polémico juicio en el que fue acusada de asesinar a Luciana Borcino. Pero Neville decidió alterar el relato de partida y dar un final más benevolente a su protagonista, cerrando El crimen de la calle Bordadores con un happy end a través de una secuencia memorable en la que la tierna criada recibirá el Perdón Real, además de lograr el amor y reconocimiento de una hija perdida hasta entonces, auténtica anagnórisis en la estela de la tradición del teatro clásico español. La pena de muerte de Higinia quedaba, por tanto, indultada cinematográficamente; resolución coherente a un planteamiento que desde los inicios transitó por el sainete humorístico, identificado a través de la estructura coral de la película, la significativa importancia de los tipos y actores de reparto, el gracejo y la frescura de sus diálogos o la condición social humilde de sus protagonistas

\footnotetext{
${ }^{9}$ Neville presentó a censura las primeras versiones del guion en 1940 y 1941, que fueron rechazadas y no será hasta 1945 cuando logre luz verde para llevar a la pantalla El crimen de la calle Bordadores. AGA, sección de Cultura, Expediente 213 y 208/45
} 
(Ríos Carratalá, 1997: 25-71).

En línea con ese planteamiento, Neville también eludió cualquier referencia política que pudiera incomodar al régimen de Franco. Suprimió la participación de personajes fundamentales en el proceso judicial (los políticos Sagasta, Canalejas o Salmerón) ${ }^{10}$, además de uno de los implicados más importantes de la causa: el director de la cárcel Modelo de Madrid, José Millán Astray, a la sazón padre del creador de la Legión y hombre fuerte del régimen franquista, José Millán-Astray Terreros.

Neville, como años después harían Azcona o Berlanga, cosechó con esta película uno de sus trabajos más sobresalientes "a través del complejo cruce del esperpento, la zarzuela, el sainete y la astracanada" (Zunzunegui, 2005: 162) y, particularmente, en su exploración del populismo casticista (Zunzunegui 2018: 26). El citado Luis García Berlanga reflexionaría, ya en 1961, sobre el poso dejado por la picaresca española "desde Quevedo a Buñuel, pasando por Goya y Solana, España se mostrará siempre igual" (García Berlanga, 1980: 42). La permanencia de dichas huellas marcará, dos años después, su siguiente film.

\section{LO GROTESCO Y LA CARNAVALIZACIÓN ESPERPÉNTICA EN UN DÍPTICO SOBRE VERDUGOS}

El verdugo (García Berlanga, 1963) es una película cuya singularidad radica fundamentalmente en su punto de vista. Tanto Berlanga como Azcona construyeron un relato que gravitaba sobre la relación entre la sociedad y ese verdugo protagonista, a quien desprecia, pero a quien también necesita. Los guionistas se situaron al lado del ejecutor, figura esencialmente secundaria cuando no casi invisible en la mayoría de las películas en torno a la pena de muerte (Gordillo, 2008: 87), humanizando a estos personajes para ahondar en sus miserias, en sus egoísmos y en sus debilidades. La empatía con su protagonista se logra porque en Amadeo (José Isbert) "no hay disonancia cognitiva entre lo que realiza y lo que entiende que debe hacer y por qué lo lleva a efecto. Este hombre dignifica su labor, recuerda a sus ajusticiados y los respeta" (Urra, 2004: 227).

\footnotetext{
${ }^{10}$ En este caso Nicolás Salmerón ejerció, junto a Francisco Silvela, la defensa de la acción popular. En 1873, Salmerón había presentado su dimisión como presidente del gobierno de la República para no tener que firmar las condenas a muerte a unos militares acusados de rebelión.
} 
El verdugo parte de un suceso real y grotesco, de gran fuerza dramática, que relató a Berlanga uno de los letrados presentes en la ejecución de Pilar Prades, más conocida como la envenenadora de Valencia, el 19 de mayo de 1959. La experiencia vivida por este abogado fue presenciar la impresionante escena de tener que empujar a víctima y verdugo a desempeñar sus respectivos papeles en el ritual de la ejecución. Los problemas comenzaron cuando el verdugo real supo que la víctima era una mujer y se negó a desempeñar su trabajo. Tras esperar más de dos horas un indulto que nunca llegó, "con una botella de coñac lograron convencerle y darle valor", aunque según cuentan los presentes en aquellos esperpénticos momentos, al final "la fuerza pública tuvo que llevar a rastras hasta el patíbulo tanto a la condenada como a su verdugo" (Costa, 2009: 18-22). Esa imagen real fue el germen de la historia compartida con Rafael Azcona, que sirvió de base de un guion que se sustentaba en la figura del verdugo Antonio López Guerra, autor, entre otros muchos, de los ajusticiamientos de Jarabo, el 4 de julio de 1959, y de Salvador Puig Antich, el 2 de marzo de 1974.

La fuerza de ese relato de lo real, la tragicomedia vivida aquella mañana de mayo en la prisión de mujeres de Valencia, se transformaron como material fílmico en el mejor obús contra la pena de muerte. Pero Berlanga fue más allá cuando, adaptando esa imagen verídica, propuso que verdugo y condenado (en el film el reo será un hombre) fueran dos víctimas de un sistema que anulaba al individuo. El potencial crítico que encierra el film no descansa únicamente en la habilidad narrativa para explotar lo insólito del suceso real sino en la complejidad estética del realismo que Berlanga maneja en su puesta en escena. En palabras de Antón:

En apariencia, se ciñe a las convenciones del realismo de la representación (realismo naturalista) formulado por el cine de Hollywood, y basado en el borrado de las huellas del acto de la representación con objeto de logar un efecto (ilusionista) de realidad. Sin embargo, este efecto de realidad es dirigido hacia un sentido social por el realismo de los contenidos, la condición genuinamente real de su universo referencial dentro del cual destaca la referencia directa a la vigencia en España de la pena capital; y este realismo de los contenidos es secundario por algunos de los estilemas de la estética baziniana: el plano de larga duración y la profundidad de 
campo (Antón, 2006: 12).

El grado de deformación de esa forma realista, por vía de la tradición hispana del humor, que podemos definir también como carnavalesca haciéndonos eco de la teoría cultural de Mijaíl Bajtín (1987), descansa en una serie de recursos (el humor negro, lo grotesco, la deformación del espacio simbólico, etc) que desactivan el efecto mistificador de la estética realista normalizada, imprimiendo al relato "un tono excesivo que colma, desbordándola, la forma habitual del realismo", determinando que el clasicismo de esta película resulte atípico, "un clasicismo fílmico derivado del realismo grotesco de la cultura popular" (Antón, 2006: 12).

El cineasta culmina la adaptación de ese referente verídico con la secuencia final de la desolada e inmensa estancia carcelaria "donde reo y verdugo se encaminan a una puerta de salida sin retorno posible, real o metafórico según los casos", la clave de todo su film (Rios Carratalá, 2007: 219). Esa pequeñísima puerta, ese desagüe concebido por el Estado, seguirá funcionando y para cuando la película de Berlanga se presente en el Festival de Venecia ${ }^{11}$, en septiembre de 1963, los ecos del fusilamiento del dirigente comunista Julián Grimau o la muerte a garrote de los anarquistas Francisco Granado y Joaquín Delgado, resonaban en el Lido. La fuerza de lo goyesco en la película formó parte de la polémica subsiguiente al estreno internacional en el certamen italiano porque los folletos repartidos entre la prensa por Ricardo Muñoz Suay reproducían un grabado de Goya, funcionando perfectamente como alusión directa a aquellas ejecuciones ${ }^{12}$.

Antonio López Guerra, el verdugo que inspiró el relato berlanguiano, fue también uno de los protagonistas de la película de Basilio Martín Patino, Queridisimos verdugos $(1977)^{13}$. Desde el cartel anunciador del film hasta su último fotograma, la película del director salmantino rezuma el poso de la tradición solanesca, apela a la herencia esperpéntica y evoca la estética de lo grotesco. La cinta enlazaba el relato sobre el pasado de las artes de matar con aquel presente, contundente y sanguinario, que se

\footnotetext{
${ }^{11}$ La película consiguió el Premio de la Crítica en ese certamen.

${ }^{12} \mathrm{El}$ grabado, en el que se está agarrotando a un hombre, pertenece a la serie Los desastres de la guerra, publicados por primera vez en 1863, un siglo antes que la producción de El verdugo.

${ }^{13}$ Queridísimos verdugos se realizó en la clandestinidad, sin apoyos estatales ni permisos de rodaje: en los créditos no constó la productora y se contrató a un equipo de Portugal para evitar posibles represalias administrativas contra los profesionales españoles.
} 
vivió durante el rodaje del film, a comienzos de los años setenta. Aunque Franco y su régimen agonizaban casi al mismo compás, las ejecuciones siguieron cayendo como pesadas losas. Patino trasladaba al espectador al humilde salón de los Martínez Expósito para mostrarnos su triste realidad y compartir con ellos los escalofriantes momentos de una ejecución en ciernes: la de su hijo Pedro, un deficiente mental. El indulto no llegó (la ejecución de la condena se realizó el 8 de enero de 1972), y la cámara captó esa terrible tensión de la imagen del silencio del padre esperando ese perdón.

De entre las distintas razones que explican la extraterritorialidad de esta película respecto al cine de principios de los setenta, como ha señalado Santos Zunzunegui, se encuentra el "singular maridaje que propone el film entre el 'realismo documental' (prudentemente entrecomillado) y el esperpento" (2018: 225-227). En el sistema de imágenes acuñado por Valle-Inclán, el esperpento es un método de revelación de lo real por vía de la deformación de las figuras y las situaciones, siendo uno de los grandes hallazgos o versiones españoles de las distintas formulaciones del distanciamiento formalista o de lo que Bertolt Brecht denominara efecto de extrañamiento (Verfremdung).

De nuevo, dentro de la dinámica incesante de movilidad intermedial, en Queridísimos verdugos, Martín Patino decidió entrar a tumba abierta en ese submundo extraño, desconocido y escabroso que rodeaba a la pena de muerte ${ }^{14}$ y utilizó la técnica de la entrevista como eje vertebrador del documento visual, convenciendo (previo pago de 250.000 pesetas) a los tres verdugos oficiales que ejercieron en España durante las tres últimas décadas para que hablaran ante la cámara: Antonio López Guerra, Vicente López Copete y Bernardo Sánchez Bascuñana. Los tres son singulares personajes que trazan, sin artificios, su propio retrato de seres marginados, delincuentes y semianalfabetos, mucho menos empáticos que los personajes de ficción construidos por Azcona y Berlanga.

La participación de estos tres verdugos en activo fue una de las bazas decisivas para la fuerza y credibilidad del film. "La técnica más sutil de 'dejar hablar al enemigo', no deja de ser otro de los grandes aciertos

\footnotetext{
${ }^{14} \mathrm{El}$ cineasta basó su película en las obras del escritor y periodista Daniel Sueiro, El arte de matar (1968) y Los verdugos españoles (1971), además del suplemento especial de la revista Triunfo 451, 23 de enero de 1971, pp. 22-55.
} 
de Patino", explica Zunzunegui (2018: 228). Además, la película utiliza no sólo a esos personajes históricos, que aportan sus testimonios para conformar un relato basado en hechos reales, sino que también incorporaba a lo largo de todo el metraje materiales (fotografías, documentos oficiales, reconstrucciones de algunos sucesos, recortes de prensa, rodaje en escenarios reales...) que reforzaban y subrayaban la verosimilitud de la impresionante crónica negra de este país. Violaciones, descuartizamientos, asesinatos, todo se irá desmenuzando desde el interior de una bodega de Badajoz, hábitat idóneo para ofrecer una radiografía de esa otra España, la España negra, mísera y humilde, la España del analfabetismo y de las desigualdades. Por eso la película utilizó también las páginas de El Caso, icono de esa España, no sólo como referente para los verdugos que siguen su actualidad y el hilo de su propio trabajo, sino como fuente primaria y fundamental de un film que conjuga el realismo documental con la visión un tanto esperpéntica de los personajes.

\section{LA REPRESENTACIÓN FÍLMICA DE LA PENA DE MUERTE EN LA TRASICIÓN DEL XX AL XXI}

La supuesta consolidación democrática generada a raíz del triunfo socialista de 1982 no significó que nuestra cinematografía abordara con más denuedo la pena de muerte, un asunto que había generado mucho sufrimiento a numerosas familias españolas pero que apenas tuvo su traslación a las pantallas cinematográficas ${ }^{15}$. José Luis García Sánchez, en La noche más larga (1991), pretendió poner el dedo en la llaga sobre la desmemoria colectiva que vivió el país en la última década del siglo $\mathrm{XX}$, recuperando uno de los más dolorosos y vergonzosos episodios del régimen franquista: los últimos fusilamientos ordenados por el dictador poco antes de morir, el 21 de septiembre de $1975^{16}$.

La película reconocía en sus créditos iniciales estar inspirada en

\footnotetext{
${ }^{15}$ Durante los años ochenta, la pena de muerte será protagonista en dos series de TVE. En 1984, Rafael Moreno Alba recreará los últimos años de lucha de la heroína liberal Mariana Pineda, ejecutada públicamente en Granada en mayo de 1831, mientras que un año después Pedro Costa produce La huella del crimen, donde se abordan los casos del crimen de la calle Fuencarral, el caso de Jarabo o el de la envenenadora de Valencia, entre otros.

${ }^{16}$ Los miembros del FRAP José Humberto Baena, José Luis Sánchez Bravo, Ramón García Sanz y los de ETA, Juan Paredes Manot y Ángel Otaegui, fueron ejecutados en Madrid, Barcelona y Burgos.
} 
hechos reales, un recurso que permitió al cineasta utilizar este parapeto para justificar por qué el film se centraba solo en los tres jóvenes ejecutados por ser miembros del FRAP, olvidando a los dos que pertenecían a ETA. García Sánchez esquivó cualquier referencia explícita a las bandas terroristas y a sus siglas porque entrar en ese terreno suponía un envite demasiado complicado. Las dificultades de dicho terreno, auténticas arenas movedizas para García Sánchez, se explican porque todo intento de recreación de un asunto tan vivo en el imaginario colectivo difícilmente iba a complacer ni a crítica ni a público. Si para algunos la película se quedaba en la superficie y no era valiente en su disección, para otros su olvido de las víctimas se consideraba una afrenta, lo que obligó al cineasta a declarar que "los hechos no pueden reproducirse nunca" numerosas imágenes extraídas del NO-DO y referencias reales como las manifestaciones antifranquistas o la petición de clemencia por parte del papa Pablo VI como elementos de contextualización. La dificultad, una vez más, no estuvo tanto en la fidelidad o no al hecho acontecido sino en la verosimilitud del relato propuesto.

\subsection{La mitificación del personaje del reo}

En plena efervescencia del debate sobre la recuperación de la Memoria Histórica en España, dos películas vinieron a revisar sendos acontecimientos sobre la pena de muerte durante la dictadura franquista: la ejecución por garrote vil de Puig Antich en Salvador (Huerga, 2006) y el fusilamiento de un grupo de mujeres en Las 13 rosas (Martínez Lázaro, 2007).

Manuel Huerga decidió centrarse en la figura de Puig Antich ${ }^{18}$ desde la recreación ficcionalizada del personaje, utilizando todas las licencias que la dramaturgia permite. La película se basaba en la novela Cuenta atrás, de Frances Escribano que, al igual que el filme, generó una intensa polémica por su "inexactitud histórica, política y filosófica" (Gordillo, 2008: 84) y por presentar "una semblanza política banal y omitiendo sucesos históricos

\footnotetext{
${ }^{17}$ Declaraciones del director a los SSII de TVE.

${ }^{18}$ El 2 de marzo de 1974, Salvador Puig Antich fue ejecutado en la prisión de Barcelona. Ese mismo día, en la prisión de Tarragona, un supuesto criminal polaco, Heinz Chez (que años después se supo era realmente de la RFA y se llamaba Georg Michael Welzel) fue también ajusticiado mediante garrote vil. De él no hay ninguna mención en la película de Manuel Huerga.
} 
relevantes en su biografía" (Domínguez, 2007: 862). Huerga dividió el film en dos partes; la primera, planteada como un thriller con elementos estéticos modernos (utilización de cómics, música de la época) y una planificación nerviosa que buscaba la conexión con un espectador joven, en la que se recurría a una voz en off explicativa del protagonista para relatarnos sus peripecias vitales. Salvador Puig Antich como personaje fílmico es un anarquista valiente, militante del MIL (Movimiento Ibérico Libertario), justiciero, guapo, encantador y familiar, enfrentado a una policía excesiva, desalmada y bestial. La película de Huerga le presenta como el "símbolo de una generación", como una víctima del franquismo a través de una mitificación (excesiva dignificación, según Domínguez, 2007: 862) en cuyas contradicciones políticas no se quiere profundizar. Para quienes le conocieron, esta imagen se sitúa en las antípodas de la realidad política de Puig Antich y del MIL (Sanz, 2004: 1-4), un movimiento estrechamente ligado a las rebeliones de los obreros en la Barcelona de los sesenta y setenta que, paradójicamente, no forman parte del film, "anunciando con ello que el contenido de la película adolecerá de contextualización histórica y política" (Domínguez, 2007: 863).

El proceso de adhesión a la dimensión humana del personaje alcanza su máxima intensidad con la sentencia de pena de muerte dictada contra Puig Antich. La película discurre entonces por el camino del melodrama carcelario, abandona su ritmo ágil y su mitología visual y musical, para volverse oscura, de planos cerrados más asfixiantes a la espera de lo irrevocable. Se recurre a elementos poco sutiles: la construcción del garrote por parte del verdugo Antonio López, la crueldad de los comentarios del policía a la hermana del condenado o la dilatada recreación hiperrealista de su muerte. En sus imágenes sobrevuela la indiferencia de la sociedad española ("los rotativos describían el juicio con total normalidad, como si se tratara de un asunto legal cotidiano, casi anecdótico" (Gómez Bravo, 2014: pos.1597) y queda en suspense si la izquierda antifranquista pudo hacer más por evitar una ejecución tan terrible como inútil ${ }^{19}$. La película no abunda en la reacción internacional a esta condena ${ }^{20}$, ni profundiza en

\footnotetext{
${ }^{19}$ Reflexiones del guionista Lluis Aracarazo en el dossier de prensa de la película. http:// manuelhuerga.com/salvador/spip.php?rubrique2 [15/03/2019]

${ }^{20}$ Desoyendo todas las peticiones de clemencia y ajenos a "la división que la aplicación de la pena de muerte generaba en determinados sectores políticos" del régimen franquista (Posición 2126), el gobierno decidió aplicar la sentencia un sábado, el 2 de marzo. Aun así
} 
"por qué no fue conmutada la pena de muerte y cómo fue instrumentalizada políticamente” (pos.1971).

Más pegada aún al encendido debate político que enfrentaba a la sociedad española sobre la ley de Memoria Histórica ${ }^{21}$ será Las 13 rosas (Martínez Lázaro, 2007), película que se centraba en un importante episodio de la represión franquista: la historia de este colectivo de mujeres (siete de ellas menores de 21 años) que fueron fusiladas en agosto de 1939 en las tapias del cementerio del Este de Madrid acusadas de ser militantes de las juventudes socialistas y comunistas ${ }^{22}$. También este film se divide en dos partes: la primera destinada a presentar a sus protagonistas, aunque aquí la narración plantea los hechos de forma fugaz y confusa, mientras que la segunda recrea tanto la vida en la cárcel de las Ventas como el proceso que llevó al fusilamiento de las chicas.

La película banaliza este acontecimiento, retrata a las mujeres como seres débiles y bastante anodinos, pasa de largo por las dificultades a las que se enfrentaron como milicianas en la guerra y reconstruye la existencia en las cárceles como espacios donde había hacinamiento, enfermedades y miseria, pero también fiestas, risas y humor. Todo resulta previsible en su desarrollo: las imágenes de torturas evidentes, las carceleras lesbianas que ofrecían privilegios a las agnósticas que pasaran por el confesionario o la solidaridad entre las heroínas. No resultan creíbles estas mujeres perfectamente maquilladas mientras sus hijos mueren de hambre. No hay credibilidad dramatúrgica, como tampoco hay verosimilitud histórica. Como explicaba el mismo realizador de Las 13 rosas el foco se centraba en los personajes, no en los sucesos históricos ${ }^{23}$, de modo que, en opinión de Rodríguez Solás, se pierde una oportunidad para dar

no pudieron evitar las protestas nacionales que se vivieron en los campus universitarios e internacionales, con los ataques a embajadas y consulados.

${ }^{21}$ El 27 de diciembre de 2007, la Ley de Memoria Histórica se publicaba en el BOE, tras haber superado los distintos trámites parlamentarios que comenzaron en diciembre de 2006 con el debate de Totalidad. Disponible en línea: https://www.boe.es/buscar/act.php?id=BOE-A-2007-22296 [29/11/2018]

${ }^{22}$ Los hechos fueron novelados por Jesús Ferrero en su libro Las trece rosas (Ferrero, 2003). En 2004, V. Vigil y J. M. Almela realizaron el documental Que mi nombre no se borre de la historia. También ese año se publicó el libro Trece rosas rojas, del periodista Carlos Fonseca (Temas de Hoy), que serviría de base al guion realizado por el escritor Ignacio Martínez de Pisón para la película de Martínez Lázaro.

${ }^{23}$ Notas del director en el dossier de prensa del film. 
poder a esos personajes que, atrapados en la estética y puesta en escena del melodrama, generan empatía en el espectador antes como víctimas que como luchadoras antifascistas:

The characters of these female prisoners are constructed undermining their political involvement, concealing their charges in the void rhetoric of the repressive fascist regime, or never really going into detail about their ideological positioning. They are depicted as victims, as suffering heroines, but never empowered as antifascists (Rodríguez Solás, 2016: 304).

\subsection{A la búsqueda de la empatía emocional del espectador}

En la estela del significativo auge que había adquirido el documental en el arranque del siglo XXI, Javier Corcuera abordó el siempre polémico asunto de la pena de muerte en Estados Unidos en uno de los episodios que componían La espalda del mundo (2000) ${ }^{24}$. El capítulo, de 28 minutos, titulado La vida, narraba las últimas horas en el corredor de la muerte de Thomas Miller ${ }^{25} \mathrm{El}$ andamiaje narrativo se edificó sobre las entrevistas a otros compañeros condenados en la prisión de Texas, contraponiendo la dureza de sus relatos o la del matrimonio mexicano que intentó frenar la de su propio hijo con las explicaciones de los funcionarios que desgranaban con fría profesionalidad los protocolos que se llevan a cabo para preparar una ejecución. Se trata de recursos propios del documental informativo que observan la realidad desde la distancia periodística aunque con un objetivo muy determinado: "Corcuera construye el documental como una operación de búsqueda de la empatía emocional del espectador" (Quintana, 2010: 68), muy en consonancia con los modos del cine norteamericano contemporáneo, que busca la identificación de la audiencia con el heroísmo de los personajes más que realizar una campaña contra la pena de muerte

\footnotetext{
${ }^{24}$ La película obtuvo una Mención Especial del Jurado Fipresci en el Festival de San Sebastián de 2000.

${ }^{25}$ En 2017, los periodistas Álvaro Corcuera y Guillermo Abril tras una investigación periodística realizaron el cortometraje documental The Resurrection Club, donde se narraba la historia de cuatro presos condenados a muerte en Estados Unidos que lograron demostrar su inocencia y quedar en libertad.
} 
en general (Papke, 2012: 1026-1027).

Por su parte, el cineasta Joan Dolç utilizó las herramientas más convencionales del cine documental en La muerte de nadie. El enigma de Heinz Ches (2003) para intentar rehabilitar la figura del supuesto polaco que fue ejecutado el mismo día que Puig Antich, pero al que apenas se dio cobertura informativa. Casi treinta años después de morir en el garrote en la prisión de Tarragona, las investigaciones periodísticas en las que se sustentaba esta reconstrucción descubrieron que Heinz Ches en realidad se llamaba Michael Welzl, no era polaco sino un alemán nacido en la antigua RDA, no era huérfano, sino que tenía mujer y tres hijos. La película revelaba que todos esos datos eran conocidos por las autoridades franquistas a través de la Interpol, aunque nunca lo declararían oficialmente, y confirmaba las hipótesis de partida: que se trataba de una condena ejemplarizante por haber matado con una escopeta de caza al guardia civil Antonio Torralba.

Construido como una investigación periodística, en la que se combinan las entrevistas a familiares alemanes con las realizadas a funcionarios del Estado español, el objetivo de este trabajo radicaba, por tanto, en desmontar todas esas informaciones que crearon un personaje conveniente para el régimen. La prensa franquista no sólo escatimaba información a los ciudadanos a través de la censura, sino que modelaba la realidad a su antojo, forjando mediante la manipulación el imaginario colectivo. Así lo atestigua la falsa identidad creada en torno a este apátrida o las fotografías retocadas para endurecer el rostro de Heinz Ches que la policía franquista entregó a los medios de comunicación para su difusión ${ }^{26}$, o incluso el mensaje subyacente del aparato represor del régimen para demostrar a la opinión pública que violencia común y violencia política se pagaban de la misma manera.

\section{CONCLUSIONES}

La representación audiovisual en la cinematografía española de un momento tan pavoroso como es la ejecución de un ser humano por parte del Estado ha sido esquivada durante décadas o dulcificada con happy ends que evitaran problemas con la censura. Así lo hemos constatado con algunas de las obras rodadas tanto en la dictadura protofascista de

${ }^{26}$ El Caso, 9 de marzo de 1974, portada. 
Primo de Rivera como en la impuesta por Francisco Franco. Cineastas como Edgar Neville decidieron alejarse del referente real e indultar cinematográficamente la pena de muerte impuesta a sus protagonistas por medio de modelos genéricos que sumaban el sainete y la comedia costumbrista. La combinación de elementos propios de la cultura y la estética popular tradicional española: lo grotesco, el esperpento, la astracanada o la tradición solanesca, que nosotros hemos abordado también como estrategias de intermedialidad, han dado como resultado algunos de los trabajos más complejos y relevantes de nuestra cinematografía. Tanto Azcona como García Berlanga o Martín Patino asimilaron toda una serie de formas estéticas autóctonas para construir renovadores planteamientos fílmicos que se convertían en la mejor estrategia de su arte contra la pena de muerte.

Si abordar este tipo de películas que proceden de personajes y hechos reales siempre conlleva dificultades (y no muchos cineastas se han atrevido a ello), el riesgo es aún mayor cuando los sucesos son contemporáneos, forman parte del imaginario colectivo de un país, sus actores o testigos siguen vivos y el referente, en definitiva, es cercano. La búsqueda de la credibilidad y la verosimilitud narrativas, objetivo primero en este tipo de obras, se verá en muchos casos cuestionada por esos otros actores de los casos (testigos, protagonistas secundarios, cómplices, colaboradores, implicados, etc), denunciando una cierta recreación romántica de los hechos o del personaje central de la trama. Esta observación se ha constatado tanto en el dibujo mitificador del héroe en Salvador, como en la falta de rigor histórico y banalización de la dimensión política de los personajes de Las 13 rosas, siendo la apuesta de ambas obras la búsqueda de la empatía emocional del espectador como víctimas pero no como sujetos de un sistema cruel e indigno cuyo máximo castigo debiera ser abolido en todo el mundo.

\section{REFERENCIAS BIBLIOGRÁFICAS}

ANTÓN SÁNCHEZ, L (2006). "Disfraz y pasión creativa: La cuestión del realismo en El Verdugo / La batalla del Boia”. En ¡Savia Nutricia? El lugar del Realismo en el Cine español [XI congreso Internacional de la Asociación Española de Historiadores del cine], 
J. Pérez Perucha y P. Poyato (eds.), 11-18. Córdoba: Filmoteca de Andalucía/A.E.H.

BAJTÍN, M. (1987). La cultura popular en la Edad Media y el Renacimiento. El contexto de FranÇois Rabelais, trad. J. Forcat y C. Monroy. Madrid: Alianza.

CÁNOVAS, J. (2014). “Los inicios del cine histórico en el imaginario fílmico español (1905-1931). En Hacer Historia con imágenes, A. L. Hueso Montón y G. Camarero Gómez (coords.), 127-148. Madrid: Editorial Síntesis.

CARRERA, P. y TALENS, J. (2018). El relato documental. Madrid: Signo e Imagen / Cátedra.

CASTRO DE PAZ, J. L.; PÉREZ PERUCHA, J. y ZUNZUNEGUI, S. (2005). La nueva memoria. Historias del cine español (19392000). La Coruña: Vía Láctea.

COSTA, P. (2009). "Garrote vil para la envenenadora". El País Semanal, 5 de julio, 18-22.

DOMÍNGUEZ RAMA, A. (2007). "Salvador (Puig Antich) en el Viejo Mundo. Algunas consideraciones históricas respecto a su recuperación mediática". HISPANIA NOVA. Revista de Historia Contemporánea 7, 861-870 (también en http://hispanianova. rediris.es/7/articulosopinion.htm [15/03/2019]).

DOW, D. R. (2000). "Fictional Documentaries and Truthfull Fictions. The Death Penalty in Recent American Film". Constitutional Commentary 17, 511-543.

GARCÍA BERLANGA, L. (1980). "Plácido y yo". En En torno a Luis García Berlanga, J. Pérez Perucha (comp.), 36-44. Valencia: Archivo Municipal del Ayuntamiento. [Publicado originalmente en Temas de cine 14-15 (1961)]

GENETTE, G. (1990). "Fictional narrative, factual narrative". Poetics Today 11.4, 755-774.

GÓMEZ BRAVO, G. (2014). Puig Antich: La transición inacabad. Barcelona: Penguin Random House Grupo Editorial [ebook].

GÓMEZ, C. y SÁNCHEZ-MESA, D. (2011). "La crónica de sucesos criminales en el discurso periodístico y el cinematográfico. El viaje de Edgar Neville entre la calle Fuencarral y Bordadores". Signa. Revista de la Asociación Española de Semiótica 20, $277-$ 304, (también en http://revistas.uned.es/index.php/signa/article/ 
view/6268 [15/03/2019]).

GORDILLO, I. (2008). "Memoria histórica y pena de muerte en España: melodrama, comedia negra y documental". Quaderns de Cine 3, 81-89.

KOZLOVSKY-GOLAN, Y. (2014). The Death Penalty in American Cinema. Criminality and Retribution in Hollywood Film. London: $\mathrm{I}: \mathrm{B}$, Tauris \& Co Ltd.

MAROTO LAVIADA, R. (2003). "El Verdugo. Escenas sombrías de una España reciente". En Cine y pena de muerte. diez análisis desde el derecho y la moral, B. Rivaya (ed.), 127-141.Valencia: Tirant lo Blanch.

MITCHELL, W. J. T. (2005). "There Are No Visual Media". Journal of Visual Culture 4.2, 257-266.

MONTERDE, J. E. (1995). "El cine de la autarquía (1939-1950)". En Historia del cine español, R. Gubern et alii, 181-238. Madrid: Cátedra.

PAPKE, D. R. (2012). "Muted Message: Capital Punishment in the Hollywood Cinema". Journalism and Mass Communication 2.10, 1019-1027 (también en https://scholarship.law.marquette.edu/ facpub/634/[18/01/2019]).

PARRO FERNÁNDEZ, I. (2008). "El tratamiento en el cine de la evolución histórica de la aplicación de la pena de muerte: de la crucifixión a la inyección letal". En Actas del I Congreso Internacional de Historia $y$ Cine, Gloria Camarero (ed.), 733-745. Getafe: Universidad Carlos III de Madrid / Instituto de Cultura y Tecnología.

QUINTANA, A. (2010). "Un oasis en medio del desierto. No ficción y creación en el cine español”. En Doc. El documentalismo en el siglo $X X I$, A. Weinrichter (ed.), 55-76. Donostia: Festival Internacional de Cine de San Sebastián.

RÍOS CARRATALÁ, J. A. (1997). Lo sainetesco en el cine español. Alicante: Publicaciones de la Universidad de Alicante.

RIVAYA, B. (2003). Cine y pena de muerte: diez análisis desde el derecho y la moral. Valencia: Tirant lo Blanch.

RODRÍGUEZ SOLÁS, D. (2016). "'I haven’t done anything wrong!' Melodrama and victimization in Las 13 rosas/13 Roses and La voz dormida/The Sleeping Voice". Studies in Spanish \& Latin American Cinemas 13.3, 303-317. 
SANZ, C. (2004). "Reflexiones 30 años después del asesinato de Salvador Puig Antich". Solidaridad Obrera 3, 1-4.

SUEIRO, D. (1968). El arte de matar. Barcelona: Ediciones Alfaguara.

URRA, J. (2004). "La soledad del verdugo". En Jauría Humana: cine y psicología, J. Urra, A. Compadre y C. Romero, 226-228. Barcelona: Gedisa.

WILLIAMS, R. (1977), “A Lecture on Realism”. Screen 18.1, 61-74.

ZUNZUNEGUI, S. (2005). "La línea general o las vetas creativas del cine español". En Castro de Paz, J. L. La nueva memoria del cine español. Historia(s) del cine español (1939-2000), 489-504. La Coruña: Vía Lactea

(2018). Historias de España. De qué hablamos cuando hablamos de cine español (edición revisada y ampliada). Santander: Shangrila.

Recibido el 25 de enero de 2019.

Aceptado el 18 de febrero de 2019. 